\title{
The study of responses to auditory processing tests in the elderly
}

\author{
Bruna Pias Peixe ${ }^{1}$ \\ https://orcid.org/0000-0003-0548-6962 \\ Taissane Rodrigues Sanguebuche ${ }^{1}$ \\ https://orcid.org/0000-0002-8614-8457
}

Vitor Cantele Malavolta 2

https://orcid.org/0000-0003-4171-1629

Michele Vargas Garcia ${ }^{3}$

https://orcid.org/0000-0003-3779-349X
Universidade Federal de Santa Maria UFSM, Programa de Pós-graduação (Doutorado) em Distúrbios da

Comunicação Humana, Fonoaudiologia, Santa Maria, Rio Grande do Sul, Brasil.

${ }^{2}$ Universidade Federal de Santa Maria UFSM, Santa Maria, Rio Grande do Sul, Brasil.

${ }^{3}$ Universidade Federal de Santa Maria UFSM, Departamento de Fonoaudiologia e Programa de Pós-Graduação em Distúrbios da Comunicação Humana, Santa Maria, Rio Grande do Sul, Brasil.

Work conducted at the Speech Therapy Course, Federal University of Santa Maria UFSM - Santa Maria, Rio Grande do Sul, Brazil.

Conflict of interests: Nonexistent

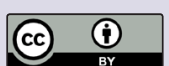

Received on: September 20, 2018 Accept on: September 11, 2019

Corresponding address:

Bruna Pias Peixe

Rua Doutor Pantaleão, nº 377 ,

apartamento 403, Bairro Centro

CEP: 97010-180 - Santa Maria, Rio Grande do Sul, Brasil

E-mail: brunapeixe.bp@hotmail.com

\section{ABSTRACT}

Objective: to generate reference values for different central auditory processing tests, investigating the influence of peripheral hearing and considering education and cognition, in the elderly.

Methods: a prospective, quantitative and cross-sectional study. The casuistry consisted of 23 elderly, aged between 60 and 81 years old, being 8 men and 14 women. Regarding the audiological characteristics, the elderly were included with normal auditory thresholds or mild and moderate sensorineural hearing loss, classified by the quadritonal average, proposed by the World Health Organization. All elderly underwent Basic Audiological Evaluation, Edinburgh Handedness Inventory, Mini Mental State Examination, and seven central auditory behavioral tests. Statistical analysis was performed using the nonparametric Mann-Whitney $U$ test.

Results: the Adapted Time-Compressed Speech Test was influenced by the peripheral hearing loss, in both ears ( $p$-value $=0,000$ ), and no significant differences were found in the other data analyzed.

Conclusion: reference values were generated for the different behavioral tests. Hearing loss influenced the results of the Adapted Time-Compressed Speech Test, suggesting that it should not be applied in the elderly with peripheral alteration. Regarding education and cognition, there was a similarity among the elderly with normal hearing thresholds and those presented with hearing loss.

Keywords: Hearing; Hearing Loss; Auditory Perception; Hearing Test; Aging 


\section{INTRODUCTION}

Aging accompanies biological changes, which are intrinsic, although influenced by environmental factors; psychological, related to the behavior of the subject; and social, interfering in his role in society ${ }^{1,2}$. Among the sensory deprivations that affect the elderly, hearing is one of the most harmful communication ${ }^{3}$. All these aspects enable social isolation, depression and reduced cognitive function ${ }^{4,5}$. Thus, the importance of studying the aging process is evident, when these facts are added to the current increase in the elderly population ${ }^{6}$.

Modifications affecting the central auditory system may damage the functioning of auditory processing, which is responsible for the efficiency with which sound information received from the peripheral system is used. This process requires auditory skills, responsible for the interpretation and analysis of stimuli ${ }^{7}$. There are numerous tests that measure these skills in situations that resemble daily living activities ${ }^{8-11}$.

The evaluation of these skills is accompanied by important particularities, as they may be influenced by education, hearing loss ${ }^{12}$, age ${ }^{13,14}$, hypertension and diabetes ${ }^{15}$. Even motivation and fatigue can compromise the subject's performance in behavioral tests ${ }^{16}$, thus explaining how delicate and individual the evaluation ${ }^{17}$.

Faced with the growing aging, and understanding the uniqueness of this population, this study had as justification, to find more appropriate reference values. This, in order to contribute to the improvement of the evaluation and the rehabilitation process of the elderly. Therefore, this study aimed to generate reference values for different behavioral tests of central auditory processing, studying the influence of peripheral hearing and considering the variables education and cognition.

\section{METHODS}

This is a prospective, quantitative and crosssectional study. This research was analyzed and approved by the Research Ethics Committee of the Federal University of Santa Maria, RS, Brazil, under number 78740117.3.0000.5346. The procedures were performed at the Audiology Clinic of a university hospital. All elderly in the sample nodded their voluntary participation, signing the Informed Consent Form, following the ethical precepts of Resolution 466/12 of the National Health Council.
The following eligibility parameters were adopted: age 60 years old or over; of both genders; Brazilian Portuguese as a native language; a minimum of three years of education, referred to; pure tone hearing thresholds within the normal or average range of 500 , 1000,2000 and $4000 \mathrm{~Hz}$ (Hertz) up to $55 \mathrm{~dB}$, using the World Health Organization classification ${ }^{18}$; minimum performance of $76 \%$ in the Percentage Index of Speech Recognition (PISR); up to $10 \mathrm{~dB}$ difference between the right and left ear auditory thresholds, configuring symmetry between the ears ${ }^{19}$.

All subjects also had right hand preference, indicated by the Edinburgh Handedness Inventory. Normality in the Mini Mental State Examination (MMSE), according to years of education, proposed in $2003^{20}$ (illiterate - 20 points; from 1 to 4 years of education 25 points; from 5 to 8 years of education - 26.5 points; from 9 to 11 years of education - 28 points, and over 12 years - 29 points). The Dichotic Digits Test (DDT) was used as a screening, so the sample presented normal performances, using the reference criterion loyal in the literature, being for normal hearing individuals: percentage greater than or equal to $78 \%$ correct; for elderly with hearing loss: score greater than or equal to $60 \%$ correct $^{21}$.

Illiterate subjects with a history of brain injury (BI), stroke, evident speech, psychiatric or neurological disorders, tympanometric curve $\mathrm{B}$ or $\mathrm{C}$ and who used the Individual Sound Amplification Device were excluded.

115 elderly people were contacted, but of these, three showed interest and could not be contacted, 14 refused to participate in the research, six were excluded due to history of stroke, three due to TBI (Traumatic Brain Injury), ten for presenting conductive impairment, 14 due to asymmetrical hearing loss, five with PISR below the inclusion criteria, three with altered MMSE, three illiterate, nine marked the evaluations, but did not attend, one due to Machado-Joseph disease and one due to present thresholds worse than $55 \mathrm{~dB}, 13$ excluded due to change in DDT and 7 due to asymmetry between ears. Finally, the sample consisted of 23 elderly, aged 60 to 81 , average of 66.6 years old, being 8 men and 14 women.

All subjects underwent the basic audiological evaluation, consisting of audiological history, visual inspection of the external acoustic meatus, pure tone audiometry, logoaudiometry and acoustic immittance measures. In addition, the Edinburgh Handedness Inventory and the MMSE were applied. 
To generate the reference values, the following tests were performed: DDT; Dichotic Sentence Identification Test (DSI); Masking Level Difference (MLD); Adapted Time-Compressed Speech Test (FCA); Randon Gap Detection Test (RGDT); Frequency Pattern Test (FPT) and Duration Pattern Test (DPT), from Auditec ${ }^{\circledR}$ version. All were applied with the intensity of $40 \mathrm{~dB}$ NS to $50 \mathrm{~dB}$ NS above the tritonal average $(500,1000$ and $2000 \mathrm{~Hz}$ ), varying according to the test.

The result of each analysis was considered significant when $\leq 0.05$, with a $95 \%$ confidence interval. For the results, descriptive analyzes were included and, in comparisons in general, the nonparametric Mann-Whitney $U$ test was used.

The mean value presents greater reliability when the results have little variation between the minimum and maximum. In the present research, these values were considered due to the representation of the variability that exists in the elderly population. In addition to the mean, for reference values, a standard deviation should be considered for each behavioral test.

\section{RESULTS}

Table 1 shows the sample descriptive data and their respective comparisons between normal hearing thresholds and hearing loss. Remembering that these elderly people had normality in DDT, used as a screening of this research. It is noteworthy that the mean values of age, education and cognition are close in both groups.

Table 1. Description and comparison of the variables age and quadritonal average for the elderly with normal hearing thresholds and those with hearing loss

\begin{tabular}{lccccccc}
\hline Variables & Report & N & Average & SD & Min & Max & P-value \\
\hline \multirow{2}{*}{ Age (years old) } & N. T. & 12 & 64.42 & 4.91 & 60.00 & 75.00 & \multirow{2}{*}{0.180} \\
& H. L. & 11 & 67.27 & 6.07 & 60.00 & 81.00 & \\
RE average (dB) & N. T. & 12 & 17.92 & 4.63 & 10.00 & 23.75 & $\mathbf{0 . 0 0 0}$ \\
& H. L. & 11 & 35.91 & 5.84 & 26.25 & 48.75 & \\
\multirow{2}{*}{ EE average (dB) } & N. T. & 12 & 16.45 & 5.09 & 5.00 & 23.75 & $\mathbf{0 . 0 0 0}$ \\
& H. L. & 11 & 35.68 & 6.00 & 28.75 & 46.25 & \\
\multirow{2}{*}{ MMSECation } & N. T. & 12 & 6.00 & 2.22 & 4.00 & 11.00 & \multirow{2}{*}{0.202} \\
& H. L. & 11 & 4.82 & 2.93 & 3.00 & 11.00 & \\
& N. T. & 12 & 28.42 & 1.62 & 26.00 & 30.00 & 0.109 \\
\hline
\end{tabular}

Legend: MMSE: Mini Mental State Examination; N: sample; SD: standard deviation; Min: Minimum; Max: maximum.

Total sample number: normal hearing thresholds: 12; hearing loss: 11.

Statistics: Descriptive analysis and Mann-Whitney U test, significant p-value $<0.05(5 \%)$.

The following are the reference values (Table 2) for the dichotic tests (DDT and DSI) and the monaurally applied FCA, organized by ear. It is evident that the higher the degree of peripheral hearing loss in the elderly, the lower the average values found for the FCA.

Table 3 shows the reference values for the central auditory processing behavioral tests, applied binaurally.
It is noteworthy that the performance of the elderly with normal thresholds was better in all tests, showing a greater difference in the DPT and RGDT tests, but without statistical difference.

Figure 1 shows the final values suggested for the elderly population, according to peripheral hearing, taking into account the use of a standard deviation. 
Table 2. Reference values and complete descriptive of monoaural and dichotic behavioral tests for the elderly with normal hearing thresholds and those with hearing loss

\begin{tabular}{|c|c|c|c|c|c|c|c|}
\hline Right ear & Report & $\mathbf{N}$ & Average & SD & Min & Max & P-value \\
\hline \multirow{2}{*}{ RE DDT } & N.T. & 12 & 93.75 & 5.49 & 85 & 100 & \multirow{2}{*}{0.192} \\
\hline & H.L. & 11 & 87.27 & 11.32 & 67.5 & 97.5 & \\
\hline \multirow{2}{*}{ RE DSI integration } & N.T. & 12 & 90.00 & 8.53 & 70 & 100 & \multirow{2}{*}{0.101} \\
\hline & H.L. & 8 & 81.25 & 13.56 & 60 & 100 & \\
\hline \multirow{2}{*}{ DSI Dir RE } & N.T. & 12 & 91.83 & 9.96 & 70 & 100 & \multirow{2}{*}{0.196} \\
\hline & H.L. & 8 & 91.25 & 9.91 & 80 & 100 & \\
\hline \multirow{2}{*}{ RE FCA } & N.T. & 12 & 71.33 & 4.77 & 64 & 80 & \multirow{2}{*}{0.000} \\
\hline & H.L. & 11 & 41.45 & 8.05 & 32 & 60 & \\
\hline Left ear & Report & $\mathbf{N}$ & Average & SD & Min & Max & P-value \\
\hline \multirow{2}{*}{ LE DDT } & N.T. & 12 & 86.83 & 5.79 & 80 & 95 & \multirow{2}{*}{0.708} \\
\hline & H.L. & 11 & 84.54 & 9.90 & 67.5 & 95 & \\
\hline \multirow{2}{*}{ LE DSI integration } & N.T. & 12 & 74.16 & 13.11 & 50 & 90 & \multirow{2}{*}{0.695} \\
\hline & H.L. & 8 & 68.75 & 23.57 & 30 & 100 & \\
\hline \multirow{2}{*}{ DSI Dir LE } & N.T. & 12 & 93.33 & 6.51 & 80 & 100 & \multirow{2}{*}{0.221} \\
\hline & H.L. & 8 & 80.00 & 23.90 & 30 & 100 & \\
\hline \multirow{2}{*}{ LE FCA } & N.T. & 12 & 73.33 & 5.99 & 64 & 80 & \multirow{2}{*}{0.000} \\
\hline & H.L. & 11 & 52.91 & 9.01 & 40 & 68 & \\
\hline
\end{tabular}

Legend: RE: right ear; LE: left ear; SD: standard deviation; Min: Minimum; Max: maximum; N: number; Dir: directed; DDT: dichotic digit test; DSI: dichotic sentence identification test; FCA: adapted time-compressed speech test.

Total number: normal hearing thresholds: 12 subjects; hearing loss 11 subjects.

Statistics: Descriptive analysis and Mann-Whitney U test. significant p-value $<0.05(5 \%)$.

Table 3. Reference values and complete descriptive of binaural behavioral tests for the elderly with normal hearing thresholds and those with hearing loss

\begin{tabular}{cccccccc}
\hline Tests & Report & N & Average & SD & Min & Max & P-value \\
\hline \multirow{2}{*}{ DPT } & N.T. & 12 & 87.78 & 12.50 & 63.33 & 100.00 & \multirow{2}{*}{0.287} \\
& H.L. & 11 & 80.00 & 18.32 & 36.66 & 100.00 & \\
FPT & N.T. & 12 & 94.99 & 6.28 & 83.33 & 100.00 & 0.379 \\
& H.L. & 11 & 92.12 & 8.73 & 70.00 & 100.00 & \\
RGDT & N.T. & 12 & 18.58 & 33.14 & 3.50 & 122.50 & 0.288 \\
& H.L. & 11 & 33.34 & 46.09 & 5.00 & 147.50 & \\
MLD & N.T. & 12 & 16.00 & 3.72 & 10.00 & 22.00 & \multirow{2}{*}{0.487} \\
& H.L. & 11 & 14.91 & 3.14 & 10.00 & 22.00 & \\
\hline
\end{tabular}

Legend: N.T .: Normal thresholds; H. L.: mild and moderate hearing loss; SD: standard deviation; Min: minimum; Max: maximum; N: number of subjects; MLD: Masking level difference; FPT: frequency pattern test; DPT: duration pattern test; RGDT: randon gap detection test.

Total number: normal hearing thresholds: 12 subjects; hearing loss: 11 subjects.

Statistics: Descriptive analysis and Mann-Whitney U test, significant p-value $<0.05(5 \%)$. 


\begin{tabular}{|c|c|c|c|c|c|c|}
\hline Tests & $\begin{array}{c}\text { Average and SD } \\
(\mathbf{N T})\end{array}$ & Ref. Value & Final Value (NT) & $\begin{array}{c}\text { Average and SD } \\
(\mathbf{H L})\end{array}$ & Ref. Value & Final Value (HL) \\
\hline RE DDT (\%) & $93.75-5.49$ & 88.26 & $\geq 87.5$ & $87.27-11.32$ & 75.95 & $\geq 75.0$ \\
\hline LE DDT (\%) & $86.83-5.79$ & 81.04 & $\geq 80.0$ & $84.54-9.90$ & 74.64 & $\geq 72.5$ \\
\hline RE DSI (\%) & $90.00-8.53$ & 81.47 & $\geq 80$ & $81.25-13.56$ & 67.69 & $\geq 60$ \\
\hline LE DSI (\%) & $74.16-13.11$ & 61.05 & $\geq 60$ & $68.75-23.57$ & 45.18 & $\geq 40$ \\
\hline RE DSI (dir) (\%) & $91.83-9.96$ & 81.87 & $\geq 80$ & $91.25-9.91$ & 81.34 & $\geq 80$ \\
\hline LE DSI (dir) (\%) & $93.33-6.51$ & 86.83 & $\geq 80$ & $80.00-23.90$ & 56.10 & $\geq 50$ \\
\hline RE FCA (\%) & $71.33-4.77$ & 66.56 & $\geq 64$ & $41.45-8.05$ & 33.40 & $\geq 32$ \\
\hline LE FCA (\%) & $73.33-5.99$ & 67.34 & $\geq 64$ & $52.91-9.01$ & 43.90 & $\geq 40$ \\
\hline DPT (\%) & $87.78-12.50$ & 75.28 & $\geq 73.33$ & $80.00-18.32$ & 61.68 & $\geq 60.00$ \\
\hline FPT (\%) & $94.99-6.28$ & 88.71 & $\geq 86.66$ & $92.12-8.73$ & 83.39 & $\geq 83.33$ \\
\hline RGDT (ms) & $18.58-33.14$ & 51.72 & $\leq 51.72$ & $33.34-46.09$ & 79.43 & $\leq 79.43$ \\
\hline MLD (dB) & $16.00-3.72$ & 12.28 & $\geq 12$ & $14.91-3.14$ & 11.77 & $\geq 10$ \\
\hline
\end{tabular}

Legend: N.T .: Normal thresholds; H. L: mild and moderate hearing loss; SD: standard deviation; DDT: dichotic digit test; DSI: dichotic sentence identification test; Dir: directed; FCA: adapted time-compressed speech test; DPT: duration pattern test; FPT: frequency pattern test RGDT: randon gap detection test. MLD: Masking level difference; Ref: reference.

* Values generated with binaural application

Figure 1. Suggested reference values for the elderly population

\section{DISCUSSION}

It is essential to highlight the proximity of the values of age, education and MMSE (Table 1), among the elderly with normal hearing thresholds and mild or moderate hearing loss. Considering cognition, it is noteworthy that the literature $e^{5,22,23}$ shows relationships between the presence of peripheral alteration and cognitive decline, which was possibly not manifested in this research, due to the fact that only elderly with normality in the MMSE were included. However, in relation to age and education, this study corroborates one conducted in the mid-2000s ${ }^{22}$, in which researchers sought to relate cognitive performance with the presence and degree of hearing loss, gender, age and education. The sample consisted of 33 elderly who underwent pure tone audiometry and MMSE, from which it was possible to conclude that only the degree of loss interfered with the cognitive performance of the elderly.

A longitudinal study ${ }^{5}$ indicated that hearing loss is associated with acceleration of cognitive decline. Developed with 1,984 elderly Americans, the results showed that when compared to elderly with normal thresholds, those with hearing loss showed $41 \%$ cognitive decline, and a $24 \%$ higher risk of developing cognitive impairment. Recently ${ }^{23}$, relationships between self-reported hearing loss and cognitive impairment were also found. These important conclusions are also derived from a longitudinal research with 3,670 subjects and a longer duration (25 years). This study highlighted the important and complex rehabilitation process ${ }^{23}$ because it pointed to the fact that the use of hearing aids does not replace integral hearing rehabilitation.

Considering this information, added to the knowledge that the elderly population is growing, both nationally and globally, it is important to evaluate, monitor and rehabilitate these subjects, so that these changes do not affect their activities of daily living and their independence, maintaining the best quality of life.

Table 2 shows the values found for the dichotic tests and those applied monaurally. It should be noted that the DDT presented better results when compared to those already existing in the literature ${ }^{21}$. This difference may be due to the fact that the referential criteria used in this study were the mean values, different from those chosen by the authors, as they considered, for the elderly with normal thresholds, the minimum of correct identifications (78\%), for subjects with loss, the lowest median value $(60 \%)^{21}$. It is not possible to compare standard deviation values between studies ${ }^{21}$, as these values were not cited during the study.

The reference values found in subjects with hearing loss (Table 2) were more similar to a group of healthy elderly than to the group with hypertension and diabetes. This recent study ${ }^{15}$ applied DDT, seeking to compare three auditory skills in the two groups above. The sample consisted of 49 participants, with a mean age of 68.06 years and normal hearing thresholds or mild sensorineural hearing loss, of which 25 elderly 
were healthy and 24 had the above changes. The average values found by the authors ${ }^{15}$ in the binaural integration stage for the healthy elderly were $87.62 \%$ for the right ear and $89.18 \%$ for the left ear, while the elderly with alterations had a mean of $78.99 \%$ for the right ear and $75.99 \%$ for the left ear. It is noteworthy that this proximity of performances occurred, even without considering the diagnosed health aspects (hypertension and diabetes) in this study. Regarding the standard deviation, both studies present high values, reflecting how much the elderly population presents a great variability in the performance in the DDT.

Regarding the results of another research ${ }^{24}$, the average values found for the elderly with normal hearing thresholds (Table 2) are slightly lower. The authors were interested in seeking the influence of aging in tests of dichotic listening and temporal ordering. For this, the sample consisted of 16 elderly, aged over 60 years old, on average 67.8 years old, with normal hearing thresholds and no cognitive impairment. For the DDT test, $95 \%$ performances were found for the right ear and $89.8 \%$ for the left ear. Even the values of this study, being lower, both found values significantly higher than the normative proposed in the work of Luz, Pereira (2000). Regarding the standard deviation values, the authors ${ }^{24}$ found 5.1 for the right ear and 9.5 for the left one, the performance variability was close in this study for the right ear, and again, lower for the left one.

Both this study and the ones mentioned above $e^{15,24}$ show a better performance of the elderly in relation to the normative values already found in the literature ${ }^{21}$. This fact demonstrates how important the proposal of the new values is for the conclusion of this test. It is also reinforced that the performance of the elderly varies greatly for the DDT test. This being a strong characteristic of this population, highlighting the importance of taking this variability into account, using the standard deviation in the analysis.

Also in the same table are the reference values for the DSI, in which it is emphasized that the performance of the elderly was not affected by hearing loss, in both stages of the test application, which corroborates the literature, since originally the DSI was developed to be applied to subjects with peripheral hearing loss, being minimally affected by $\mathrm{it}^{25}$. Therefore also, in their version of Brazilian Portuguese, the authors first sought reference values for the population with good hearing acuity ${ }^{26}$. It is also noteworthy that the values of the directed listening stage are better than in the binaural integration stage, corroborating the findings of this recent study ${ }^{26}$, which pointed out that in the directed stage, subjects without central auditory processing disorder are able to direct your auditory attention.

When the DSI performances are compared between the ears, it is noticed that the right ear has better results in both stages of the test (Table 2). This information corroborates the study that aimed to generate reference values for the $\mathrm{DSI}^{26}$. The research consisted of a sample of 200 subjects with normal thresholds, aged between 13 and 49 years old, which showed a superior performance of the right ear, as the age increased.

This advantage of the right ear is also exposed in a sample of the elderly in another dichotic test ${ }^{27}$. Moreover, these authors suggest the introduction of these tests in the central auditory processing evaluation battery, in this age group, as it provides early identification of the degenerative processes present in aging. Since this difference between the ears may be caused by a progressive degradation of the corpus callosum, also promoted by aging, reducing the efficiency of interhemispheric transfer ${ }^{28}$. The authors of this study reinforce the importance of including dichotic tests in the evaluation, since as it may evidence a degeneration, the speech therapist may make a referral for more targeted evaluations. This enables an earlier identification of these changes, benefiting the intervention.

Regarding the performance of the elderly in the FCA (Table 2), it is important to highlight that the hearing loss influenced the performance of the elderly in both ears. As well as the sample subjects showed difficulty and discomfort in performing this test, due to the great difficulty to which they were exposed, most of the time, the elderly invented the test responses. Therefore, the authors of this study do not indicate its performance in the elderly population with hearing loss. When the values are compared with the Compressed Speech (CS), original version, with disyllable words, a study already addressed above ${ }^{15}$ shows that the elderly with normal thresholds had similar values in the FCA, since the values for healthy elderly found by the authors, were $70.96 \%$ for the right ear and $68 \%$ for the left one. This fact indicates that the adaptation of the tes ${ }^{11}$ did not influence the performance of the subjects when compared to the original test ${ }^{10}$. There is less variability in the responses of the elderly in this research, indicated by the standard deviation values, considering that the results for the right and left ears, respectively, were 11.84 and 14.36. This deviation-related difference may be due to the lower number of words in the adapted version. 
Recently, other authors ${ }^{29}$ also applied CS, with disyllable words, in the elderly, seeking to evaluate their performance in general. The sample consisted of 22 subjects, aged 60 to 80 years old, normal hearing thresholds or mild sensorineural hearing loss. The authors performed the test application on random ears. Therefore, they found no difference between the ears, however, the best performance was that of the second ear started. Their results were inferior to those of the adult population. Regarding the performances, the average obtained for the right ear was $73.81 \%$ and $72.36 \%$ for the left one. The values of the elderly with normal thresholds in this study (Table 2) are close to those found, reinforcing the hypothesis that the adaptation of the instrument did not influence the test results. Regarding the standard deviation values ${ }^{29}$, for the right and left ears, respectively, were 10.77 and 13.36, again, this study presented less variability for the FCA, which may be due to the lower number of words.

The values shown in Table 3 show that in the RGDT and DPT tests, which evaluate the resolution skills and temporal ordering, respectively, the elderly who presented hearing loss had a worse performance. This fact was also demonstrated by a study ${ }^{12}$ that sought to analyze the effect of hearing loss, education and age on the temporal processing of the same population. The authors evaluated the abovementioned skills in 30 elderly, divided into two groups, according to their audiological reports. The tests used for the evaluations were GIN and $\mathrm{DPT}^{8}$. They found that hearing loss only influenced the temporal resolution skill.

Regarding temporal ordering ${ }^{30}$, even if the difference was not confirmed by statistical analysis, the mean value for the group with normal thresholds was $84.6 \%$ and those with hearing loss $78 \%$ for $\mathrm{DPT}^{8}$. On the other hand, the opposite occurs in the melodic version, since the normal hearing elderly averaged $84 \%$ and those with hearing loss had an average of $89 \%$. These facts regarding DPT ${ }^{12,30}$ can be explained by the use of different versions of it. However, the authors of this study emphasize the evidence that the Auditec ${ }^{9}$ version is easier to apply to the elderly population (longer duration of stimuli), compared to another version ${ }^{8}$. It is also highlighted that different normalities should be used according to the audiological report presented by the elderly, in order to seek the best way to represent their difficulties.

In this study (Table 3), considerably better performances in DPT and FPT are noticed when compared to other studies found in the literature ${ }^{31,32}$. In order to evaluate central auditory processing in the elderly population and to verify if hearing loss influences their performance, the authors ${ }^{31}$ applied the DPT ${ }^{8}$. The study included 65 elderly people, divided into three groups, according to the audiological reports. As hearing loss did not interfere with the results, the average of correct responses in the general sample was $63.1 \%$. The overall standard deviation value was 25.4 , indicating, as in this study, a large variability related to the performance of the elderly. This oscillation of this research is smaller, but still, it is considered high. The authors ${ }^{31}$ discuss the possibility of this variation being related to other aging factors.

The second research mentioned ${ }^{32}$ performed the DPT and FPT tests, Auditec $\AA^{9}$ version, seeking to verify the effects of a hearing rehabilitation program for temporal ordering in elderly hearing aid users. Therefore, the sample consisted of 17 subjects with hearing loss, divided into two groups, the control, made up of hearing aid users and the study, in which hearing aid users performed rehabilitation. The values for the control group in the initial study evaluation were $51.93 \%$ for DPT and $82.64 \%$ for FPT. The increase in the values of this study is evident, even compared to the performance of the elderly with hearing loss (Table 3). Not only are the performances considerably better, but the elderly in this study showed great response variability, but even lower than those found by Hennig et al., $2012^{32}$. The value for the DPT was 31.85 and for the FPT, 19.81 .

These better performances are also evidenced when compared to another population ${ }^{33}$ that also used the Auditec ${ }^{\circledR}$ version tests in adult subjects. The authors ${ }^{33}$ analyzed the effects of age on temporal processing. To this end, the sample consisted of adults divided into two groups, the first consisting of 10 subjects from 35 to 45 years old and the second, also with 10 adults, from 46 to 55 years old. The mean values found for older adults were $74.3 \%$ for DPT and $67.3 \%$ for FPT. Two points differ in this study, besides the values being considerably higher, the performance of the elderly in the FPT is better than in the DPT, both for the elderly with normal thresholds and those with hearing loss. However, the latter may be a characteristic of the elderly population, since FPT also obtained better results in the other research mentioned ${ }^{32}$.

Considering the values found, shown in Table 3, for the RGDT, a better performance of the elderly with normal thresholds is observed when compared to a recent study ${ }^{34}$ conducted in the same population. The 
authors investigated which test has the best sensitivity to evaluate temporal resolution, comparing RGDT and GIN, and suggesting reference values for both. The value found for the RGDT was $23.13 \mathrm{~ms}$, but this divergence between reasearch may be a consequence of the difference between the casuistry among them, since the sample composed by the authors ${ }^{34}$ included elderly with and without hearing loss, without group separation, as well as, the value used by the study was the median. Regarding the oscillation of responses, indicated by the value of the standard deviation, this study corroborates with Vellozo et al. (2016) ${ }^{34}$, which points to a value of 40.04 .

Regarding the performance of the elderly with hearing loss, there is also a divergence between the values, when compared to another recent research ${ }^{35}$. The authors sought to measure the relationship between the functioning of hearing skills and cognitive aspects. For this, the 12 elderly participants, with a mean age of 68.3 years old, presented mild to moderate sensorineural hearing loss. Their average was $21.3 \mathrm{~ms}$ before the fitting and use of hearing aids. Even between two groups with the same auditory characteristics, this study indicated a significantly higher average. The study does not expose standard deviation values.

Comparing the values with another study ${ }^{15}$, discussed above, there is a similarity between the elderly with normal thresholds of this study, and the healthy subjects evaluated by Bruno et al. (2015) ${ }^{15}$. When temporal resolution skill was evaluated with the RGDT test, they found an average of $19.39 \mathrm{~ms}$. This similarity in the test performance does not occur when considering the variability of the results, since the value of the standard deviation was $18.37^{15}$. Although both present a great variation, the values present considerable differences.

These divergences mentioned above may be due to the great performance variability found in the elderly population. This is also emphasized when the standard deviation values are observed both in this research and in the studies mentioned here. This variation is possible due to the influence of aging on temporal aspects, as well as on individual hearing experiences. A high value of standard deviation sometimes ends up not generating studies with good reliability, however, it is noticed that it is a strong characteristic of the elderly.

The importance of reaching the best way to evaluate temporal resolution auditory skill is highlighted, as it is closely related to speech intelligibility ${ }^{36}$, being responsible for distinguishing or resolving sound stimuli ${ }^{37}$. A valuable guideline that should be given to the elderly or their caregiver is that it is not always necessary to speak stronger, since it is pointed out ${ }^{38}$ that, regardless of the peripheral condition, message recognition is facilitated when speech is performed at a slower speed and in silence.

Table 3 also shows the reference values for MLD, the averages found for the group of elderly with normal thresholds and those with hearing loss, are close. However, it is remarkable how much larger they are when compared to a study ${ }^{39}$ that sought to point out reference values. The sample consisted of 30 subjects, aged 18 to 39 years old, of these, $73.34 \%$ had values equal to or greater than $7 \mathrm{~dB}$, and this value, considered normal, this study did not present the standard deviation value found. Another recent study ${ }^{40}$ also sought to contribute with reference values in the same population. A total of 109 women aged 20-30 years old with normal thresholds were included in the sample. The average value found was $10.83 \mathrm{~dB}$. This research also obtained higher values, so it is hypothesized how sensitive this test is to changes in the skill of selective attention in the elderly, since even compared to adults, they performed better, and it is important to highlight that the worst result found (minimum) was 10 $\mathrm{dB}$, and the standard deviation value is 3.30. Regarding this result, this research corroborates the recent study ${ }^{40}$ because both point to little response variability for MLD. This doubt of how sensitive this test is to the elderly population suggests what the scientific community needs further studies in order to unravel this issue.

It is emphasized that the hearing history of the elderly exponentially influences the behavioral evaluation, not only the audiological report itself, but also the time of sensory deprivation in which the elderly are exposed. Therefore, in an attempt to make the application of central auditory processing tests more appropriate, it is suggested and emphasized the use of a standard deviation (Figure 1), even though it is not a small value, as they are strictly related to the great variability of the performance of the elderly.

\section{CONCLUSION}

It was possible to generate the reference values for the behavioral tests applied here. In addition, the progression of hearing loss influenced the results of the FCA, indicating that its application is not advisable in the elderly with peripheral alteration. There was a close proximity to the average of education and performance in a cognitive screening test among the elderly with normal hearing thresholds and mild or moderate hearing loss. 


\section{REFERENCES}

1. Dibner AS. The psychology of normal aging. In: Spencer MG, Dorr CJ (eds). Understanding of aging: a multidisciplinary approach. New York: Appleton-Century-Crofts; 1975.

2. Ribeiro A. Aspectos biológicos do envelhecimento. In: Russo ICP (org). Intervenção fonoaudiológica na terceira idade. Rio de Janeiro: Revinter; 1999. p. 1-11.

3. Russo ICP, Almeida K, Freire KGM. Seleção e adaptação da prótese auditiva para o idoso. In: Almeida K, lorio MCM (orgs). Próteses auditivas: fundamentos teóricos \& aplicações clínicas. $2^{\circ}$ edição. São Paulo: Lovise LTDA; 2003. p. 385-407.

4. Lin FR, Metter EJ, O'brien RJ, Resnick SM, Zonderman A, Ferrucci L. Hearing loss and incident dementia. Arch Neurol. 2011;68(2):214-20.

5. Lin FR, Yaffe K, Xia J, Xue QL, Harris TB, PurchaseHelzner $E$ et al. Hearing loss and cognitive decline in older adults. JAMA internal medicine. 2013;173(4):293-9.

6. Instituto Brasileiro de Geografia e Estatística IBGE: Atlas do censo demográfico 2010. Editor: IBGE. Rio de Janeiro. Cap. 3, 2013. Disponível em: http://censo2010.ibge.gov.br/

7. Samelli AG, Mecca FFN. Treinamento auditivo para transtorno do processamento auditivo: uma proposta de intervenção terapêutica. Rev. CEFAC. 2010;12(2):1-7.

8. Musiek FE, Baran JA, Pinheiro ML. Duration Pattern recognition in normal subjects and patients with cerebral and cochlear lesions. Audiology. 1990;29(6):304-13.

9. Auditec. Evaluation manual of pitch pattern sequence and duration pattern sequence. St Louis: Auditec; 1997.

10. Rabelo CM, Schochat E. Time-compressed speech test in Brazilian Portuguese. Clinics. 2007;62(3):261-72.

11. Folgearini JS, Goulart LLA, Silva DD, Vellozo FF, Mezzomo CL, Garcia MV et al. Time-compressed speech test: adaptation and validation. Rev. CEFAC. 2016;18(6):1294-301.

12. Lima IMS, Miranda-Gonsalez EC. Effects of age, schooling and hearing loss on temporal processing in elderly. Rev. CEFAC. 2016;18(1):33-9.

13. Braga BHC, Pereira LD, Dias KZ. Normality tests of temporal resolution: Random Gap Detection Test and Gaps-In-Noise. Rev. CEFAC. 2015;17(3):836-46.
14. Deperon TM, Silva IMC, Caldas FF, Mendes BCA, Novaes BCAC. Auditory Temporal Processing in Elderly. Distúrb. Comun. 2016;28(3):530-8.

15. Bruno RS, Pelissari I, Brückmann M, Biaggio EPV, Garcia MV. Habilidades do processamento auditivo em idosos saudáveis e idosos hipertensos e diabéticos. RBCEH. 2015;12(2):111-22.

16. American Speech-Language-Hearing Association ASHA. (Central) Auditory Processing Disorders-The Role of the Audiologist, 2005. Disponível em: www. asha.org/policy.

17. Murphy CFB, La Torre R, Schochat E. Association between top-down skills and auditory processing tests. Braz J Otorhinolaryngol. 2013;79(6)753-9.

18. World Health Organization. Prevention of blindness and deafness: grades of Hearing impairment. [2014]. Disponível em: http://www.who.int/pbd/ deafness/hearing_impairment_grades/en/

19. Newton VE, Rowson VJ. Progressive sensorineural hearing loss in childhood. $\mathrm{Br} J$ Audiol. 1988;22(4):287-95.

20. Brucki SMD, Nitrini R, Caramelli P, Bertolucci PHF, Okamoto IH. Sugestões para o uso do Mini-Exame do Estado Mental no Brasil. Arq Neuropsiquiatr. 2002;61 (3):777-81.

21. Luz SV, Pereira LD. Teste de escuta dicótica utilizando dígitos em indivíduos idosos. Acta Awho. 2000;19(4):180-4.

22. Kopper H, Teixeira AR, Dorneles S. Desempenho cognitivo em um grupo de idosos: influência de audição, idade, sexo e escolaridade. Arq Int Otorrinolaringol. 2009;13(1):39-43.

23. Amieva H, Ouvrard C, Giulioli C, Meillon C, Rullier L, Dartigues JF. Self-reported hearing loss, hearing aids, and cognitive decline in elderly adults: a 25 -year study. J Am Geriatr Soc. 2015;63(10):2099-104.

24. Pereira LD, Dias TLL, Andrade AN. Escuta dicótica, ordenação temporal e o processo de envelhecimento saudável. Estud. Interdiscipl. Envelhec. 2016;21(3):145-59.

25. Fifer RC, Jerger JF, Berlin Cl, Tobey EA, Campbell JC. Development of a dichotic sentence identification test for hearing-impaired adults. Ear Hear. 1983;4(6):300-5.

26. Andrade AN, Gil D, lório MCM. Valores de referência para o teste de identificação de sentenças dicóticas em português brasileiro segundo orelha e idade. Braz J Otorhinolaryngol. 2015;81(5):459-65. 
27. Gonçales AS, Cury MCL. Assessment of two central auditory tests in elderly patients without hearing complaints. Braz $\mathrm{J}$ Otorhinolaryngol. 2011;77(1):24-32.

28. Baran JA, Musiek FE. Avaliação comportamental do sistema nervoso auditivo central. In: Musiek FE, Rintelmann WF (eds). Perspectivas atuais em avaliação auditiva. Barueri: Manole; 2001. p.371-409.

29. Arceno RS, Scharlach RC. Time-compressed speech test in the elderly. CoDAS. 2017;29(5):1-6.

30. Mesquita LG, Pereira LD. Processing time in the elderly: the effect of the ability to temporal resolution in jobs of ordering a series of sounds. Rev. CEFAC. 2013;15(5):1163-9.

31. Liporaci FD, Frota SMMC. Envelhecimento e ordenação temporal auditiva. Rev. CEFAC. 2010;12(5):741-8.

32. Hennig TR, Costa MJ, Rossi AG, Moraes AB. Efeitos da reabilitação auditiva na habilidade de ordenação temporal em idosos usuários de próteses auditivas. J. Soc. Bras. Fonoaudiol. 2012;24(1):26-33.

33. Miranda-Gonsalez EC, Alvarez LS. Os efeitos da idade no processamento auditivo temporal em adultos. Arq Med Hosp Fac Cienc Med Santa Casa São Paulo. 2016;61(3):123-7.

34. Vellozo FF, Schwantes AL, Souza AEH, Peixe BP, Biaggio EPV, Martins QP et al. Temporal resolution in elderly. Rev. CEFAC. 2016;18(2):355-61.

35. Lessa $A H$, Costa MJ. The influence of cognition on the auditory skills of the elderly: pre- and post-hearing aid fittings. Audiol., Commun. Res. 2016;21 (sup.):1-7.

36. Eggermont JJ. Neural responses in primary auditory cortex mimic psychophysical, acrossfrequency-channel, gap-detection thresholds. J Neurophysiol. 2000;84(3):1453-63.

37. Shinn JB. Temporal processing: the basics. Hear J. 2003;56(7):52.

38. Lessa $\mathrm{AH}$, Costa MJ. The impact of speech rate on sentence recognition by elderly individuals. Braz J Otorhinolaryngol. 2013;79(6):745-52.

39. Paula PS, Frota S, Felipe L. Masking Threshold Differential (MLD): pilot study. Int Arch Otorhinolaryngol. 2012;16(suppl. 1):102.

40. Mendes SC, Branco-Barreiro FCA, Frota S. Masking level difference: reference values in adults. Audiol., Commun. Res. 2017;22(e1746):1-5. 